\title{
Discursividades sobre identidade, sexualidade e feminismo em redes sociais
}

\author{
Maria de Lourdes Rossi Remenche' (iD) 0000-0003-3283-9890 \\ Paulo Henrique Machado' (iD 0000-0002-6459-7526 \\ Nívea Rohling 1 (D) 0000-0003-2797-9207
}

'Universidade Tecnológica Federal do Paraná, Programa de Pós-Graduação em Estudos de Linguagens, Curitiba, PR, Brasil. 80230-901 - ppgel-ct@utfpr.edu.br

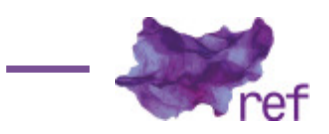

\begin{abstract}
Resumo: Este artigo analisa a discursividade performativa a respeito da identidade, da sexualidade e do feminismo a partir de postagens realizadas pela rapper curitibana Karol Conka em sua fanpage no Facebook, referentes ao lançamento de seu videoclipe Lalá. Os referenciais teóricos para o desenvolvimento desta pesquisa ancoram-se nos estudos da Linguística Aplicada e na concepção dialógica da linguagem do Círculo de Bakhtin. A partir da análise das cadeias enunciativas produzidas na fanpage da artista, é possível problematizar os modos como as redes sociais na Internet contribuem para a ressignificação das práticas de linguagem e vêm se caracterizando como espaço-tempo significativo de embate de vozes, bem como ambiente de posicionamento performativo. Os resultados evidenciam que, na enunciação dos sujeitos, são mobilizadas forças centrífugas e forças centrípetas. Palavras-chave: discursividade; identidade; sexualidade; feminismo; Linguística Aplicada.
\end{abstract}

\section{Discursivities about Identity, Sexuality and Feminism in Social Networks}

Abstract: This article analyzes the performative discursiveness on identity, sexuality and feminism from the posts made by the Curitiba's rapper Karol Conka in her fanpage on Facebook, referring to the launching of her music video Lalá. The theoretical references for the development of this research are anchored in the studies of Applied Linguistics and in the dialogical conception of Bakhtin's Circle language. From the analysis of the enunciative chains produced in the fanpage of the artist, it is possible to problematize the ways in which social networks on the Internet contribute to the re-signification of language practices and are characterized as significant space-time of voice clash, as well as performative positioning. The results show that, in the enunciation of the subjects, are mobilized centrifugal and centripetal forces.

Keywords: Discursiveness; Identity; Sexuality; Feminism; Applied Linguistics.

\section{'Causando um tombamento' no ciberespaço}

A Linguística Aplicada (LA) tem buscado uma agenda de pesquisa inter/trans/multidisciplinar (Kanavillil RAJAGOPALAN, 2008), que, por problematizar a relação entre linguagem, identidades, subjetividades e letramentos à luz de teorias discursivas, sócio-históricas e culturais, torna-se mestiça, fronteiriça, movediça e nômade, ou seja, um campo de pesquisa indisciplinar e transgressivo (Luiz Paulo da MOITA LOPES, 2008; Alastair PENNYCOOK, 2008). Nesse campo, as investigações são situadas, isto é, consistem em estudos que possibilitam a análise desses processos a partir de onde e do modo como são discursivisados, com vistas a perscrutar os sujeitos sociais que, juntamente com a linguagem e as línguas, movem-se em uma sociedade hiperssemiotizada, fluida e fragmentada (MOITA LOPES, 2013a). Assim, na contemporaneidade, tem-se uma LA engajada, que se conecta às questões de discurso, identidade, ideologia, gênero, sexualidade, raça, etnia, classe social, cultura, política (PENNYCOOK, 2008) e que clama pela escuta dos grupos sociais 
considerados à margem da sociedade, não podendo desconsiderar o viés "intercultural, interlinguístico e interdisciplinar" (Bala KUMARAVADIVELU, 2008, p. 139).

Tal agenda de pesquisa remete a uma discussão dialógica que demanda articulação de questões emblemáticas: noções de sujeito, identidade e linguagem nas práticas de letramentos na modernidade recente. Soma-se a isso as questões de linguagem relacionadas à globalização e ao advento da Web 2.0 que, aliadas à popularização dos computadores pessoais e dos dispositivos eletrônicos portáteis, têm apontado para mudanças no uso de recursos expressivos mobilizados no ambiente digital, alterando sobremaneira as formas de ler, de escrever, de estar e agir no mundo.

A Internet tem possibilitado que novos modos de se posicionar na sociedade sejam incorporados pelos sujeitos com acesso aos recursos de comunicação e interação disponíveis online, sobretudo aqueles disponibilizados pelas redes sociais virtuais, constituídas por interações que agregam identidades por afinidades.

Os sites de redes sociais permitem aos indivíduos, por meio de perfis públicos ou semipúblicos, articular uma lista de outros usuários com os quais compartilham uma conexão e visualizar a lista de conexões feitas por outras pessoas no sistema, ajudando desconhecidos a se conectarem com base em interesses compartilhados, opiniões políticas ou atividades (Danah M. BOYD; Nicole B. ELLISON, 2007).

Dentre essas redes sociais digitais, o Facebook, lançado em 2004, se destaca. Ele é utilizado, em geral, para compartilhamento de conteúdo como fotos, vídeos e outros textos, e se constitui em espaço-tempo em que os atores sociais estabelecem relações interpessoais em diversos campos. Nesse ambiente, os gêneros discursivos passaram a acionar diferentes semioses no processo de significação, a partir da "possibilidade de agregar à escrita verbal outras linguagens como imagens dinâmicas e sons diversos" (Antônio Carlos XAVIER, 2013, p. 16).

Os serviços disponibilizados pelos sites de redes sociais abrangem um conjunto de novas tecnologias comunicacionais mais participativas e as apropriações sociais que são geradas em torno dessas ferramentas. Tais serviços possibilitam que os sujeitos disputem este espaço interativo no que se refere ao número de visualizações e engajamento em suas postagens. Esse fenômeno não passa despercebido por organizações de todas as áreas, que por intermédio de suas páginas institucionais no Facebook, denominadas fanpages, transformam as práticas e formas de agir e se comunicar a partir da inclusão dos recursos e funcionalidades disponíveis no ciberespaço, promovendo a imagem institucional junto a seus públicos-alvo (BOYD; ELLISON, 2007). Raquel Recuero (2013) explica que o engajamento é decorrente do envolvimento dos usuários de uma rede social entre si e com a marca como persona. É a construção de laços mais fortes, de capital social naquele espaço e naquela rede. Com isso, a rede deixa de ser só uma rede social e passa a ser um espaço de comunidade. Esses usuários deixam de ser mera audiência e passam a ser construtores do discurso do serviço também, porque replicam, comentam, discutem com os amigos e recomendam o serviço ou a marca.

A convergência das mídias oferecida pelo Facebook tem possibilitado a veiculação de composições multimodais cada vez mais atraentes, capazes de encaminhar (linkar) os usuários para outros sites, redes e mídias sociais, por meio de uma trama hipertextual dinâmica. Essa estratégia de remodelagem nas formas de acesso aos bens culturais tem sido utilizada nos últimos anos, especialmente por artistas e produtores musicais, por meio de suas fanpages, criadas especialmente para serem canais de comunicação com admiradores dentro da rede social.

A rapper curitibana Karol Conka' tem se destacado no cenário artístico contemporâneo por meio das redes sociais, sobretudo, pelas postagens multimodais de trechos das letras de suas canções, que tematizam sexualidade, racismo, entre outros tabus. Negra e de origem humilde, a cantora se tornou um símbolo de resistência para as mulheres, por se posicionar politicamente em prol do empoderamento feminino e em defesa do movimento feminista no Brasil. Teve a carreira alavancada pelo Canal KondZilla - maior produtor de conteúdo audiovisual de música eletrônica de periferia no Brasil -, que publicou o videoclipe do single Tombei em seu canal no YouTube, em março de 2015. Além das mais de 20 milhões de visualizações do vídeo (em março de 2017), Tombei popularizou expressões como 'Mamacita fala, vagabundo senta' e 'tombamento', além de prêmios musicais e destaque em televisão aberta (Lucas BRÊDA, 2017).

Contudo, em junho de 2017, a partir dos anúncios de pré-estreia e da efetiva publicação do videoclipe do single Lalá, ${ }^{2}$ em que a estética, as performances executadas e os posicionamentos defendidos pela artista (normalmente antecedidos e/ou precedidos pelas hashtags \#Lalá e \#MeLambelá) acabaram por gerar acalorados embates discursivos por meio de postagens e comentários online, caracterizando os domínios de Karol Conka nas redes e mídias sociais em verdadeiras arenas discursivas. Em outras palavras, "um espaço de disputa ideológica, marcado pela tensão entre discursivizações díspares" (Anderson Salvaterra MAGALHÃES;

\footnotetext{
${ }^{1}$ Nome artístico de Karoline dos Santos Oliveira, nascida em 1 de janeiro de 1987, na cidade de Curitiba/PR. É cantora de rap, compositora, atriz, produtora, modelo e apresentadora.

' Lalá é a abreviação vocabular que Karol Conka criou para a expressão 'Lambida lá'.
} 
Maria Elizabeth da Silva QUEIJO, 2015, p. 169), em que, na enunciação dos sujeitos, se cruzaram as forças centrípetas (centralizadoras, estabilizadoras) e as forças centrífugas (descentralizadoras, desestabilizadoras) da língua (Mikhail BAKHTIN, 2015).

Esse episódio evidencia o fato de que as redes sociais na Internet contribuem para a produção e circulação de enunciados de contestação que dialogam, isto é, de embates de contraposição e de intenso e tenso enfrentamento.

Nesse contexto discursivo, o presente artigo analisa a "discursividade performativa" 3 (Thayse Figueira GUIMARÃES; MOITA LOPES, 2016), isto é, discursos-respostas materializados em comentários online a respeito da identidade, da sexualidade e das formas de exercício do feminismo, a partir de três postagens realizadas por Karol Conka em sua fanpage no Facebook, referentes ao lançamento do videoclipe Lalá, hospedado no YouTube. A análise empreendida tem como parâmetro teórico-metodológico os conceitos bakhtinianos acerca da dimensão dialógica/ axiológica da linguagem. A partir da análise das cadeias enunciativas produzidas na fanpage da artista, é possível problematizar os modos como as redes sociais na Internet contribuem para a ressignificação das práticas de linguagem e vêm se caracterizando como relevante espaçotempo de embate de vozes, bem como ambiente de posicionamento performativo.

Apresenta-se na sequência um breve percurso de perspectivas teórico-conceituais a respeito da LA na contemporaneidade, da linguagem e do discurso. Posteriormente, tendo como base metodológica a concepção bakhtiniana de linguagem, de discurso e de enunciado, em consonância com as contribuições da LA 'indisciplinar', é apresentada a análise empreendida que evidencia a arena discursiva em @karolconka (Karol CONKA, 2017) acerca dos temas identidade, sexualidade e feminismo.

\section{Linguagem e discurso nos estudos bakhtinianos}

Este estudo assume como base teórico-metodológica a concepção bakhtiniana de linguagem, de discurso e de enunciado (BAKHTIN, 201 1; 2015; 2016; Valentin VOLOCHÍNOV, 2017), amparando-se na agenda de pesquisa abarcada pela LA na contemporaneidade.

Na perspectiva de Volochínov (2017), a concepção de linguagem é intrínseca ao seu uso, portanto, inserida no bojo das atividades humanas, possui caráter social, histórico e ideológico. 0 autor entende a linguagem como um lugar de ação e interação, a qual não pode ser compreendida apenas como corpus de estudo específico da Linguística, pois precisam ser consideradas as esferas física, psicológica, fisiológica e social. A enunciação - produto da interação entre sujeitos socialmente organizados - se constitui em diálogo a partir de um conhecimento que é, ao mesmo tempo, pessoal e histórico. Por conseguinte, a palavra - sempre ideológica e vivencial - é o elemento privilegiado da comunicação cotidiana, por estar presente em todos os atos de interpretação e de compreensão, ou seja, ela nunca é um produto da expressão individual de um sujeito, é sempre dirigida a um interlocutor.

Todo discurso nasce no diálogo como sua réplica viva, pois é constituído da palavra alheia (o encontro com o horizonte subjetivo do ouvinte - o auditório social), em uma heterodiscursividade social que traduz a estratificação interna da língua e abrange a diversidade de todas as vozes socioculturais em sua dimensão histórico-antropológica (BAKHTIN, 2015).

Assim, a concepção de discurso contempla uma dimensão semiótica e uma dimensão social. Na visão do Círculo de Bakhtin, o sujeito, ao se enunciar, não toma as formas da língua de um sistema de signos abstraído das relações sociais e interativas, pois as formas linguísticas se lhe apresentam como elementos de interações e de enunciados particulares, situados em contextos socioideológicos situados. Como sintetiza Volóchinov (2017), "a realidade efetiva da linguagem [...] é [...] o acontecimento social da interação discursiva que ocorre por meio de um ou de vários enunciados" (p. 218-219).

Assim, com base no eixo do pensamento bakhtiniano da dimensão dialógica/axiológica da linguagem, a relação do sujeito com o mundo é sempre atravessada por valores materializados nos signos ideológicos, ou seja, é semioticamente mediada e não direta. Desta maneira, não há um mundo que se dá a conhecer, mas versões do mundo que são refratadas valorativamente nos signos. Volóchinov (2017) observa que "na composição de sentido não há nada que esteja acima da formação e independente da ampliação dialética do horizonte social. A sociedade em formação amplia a sua percepção da existência em formação" (p. 238). Portanto, nesse processo, "a significação [...] é absorvida pelo tema e dilacerada por seus conflitos vivos, para depois voltar como uma nova significação com a mesma estabilidade e identidade transitórias" (VOLÓCHINOV, 2017, p. 238).

Na contemporaneidade, considerando o contexto efervescente das práticas de linguagem em ambientes digitais, é fundamental a admissão de que os gêneros discursivos passaram por um

\footnotetext{
${ }^{3}$ A teoria da performance é apontada como uma alternativa às teorizações pautadas em uma perspectiva essencialista de linguagem, constituindo um conceito útil na construção de conhecimentos sobre fenômenos sociais.
} 
processo de conectividade, entendido como "as diversas formatações e convergências por que passam as práticas discursivas na Web" (Júlio ARAÚJO, 2016, p. 52). Dessa maneira, com o surgimento de práticas específicas em meio digital, as modalidades tradicionais do discurso foram profundamente afetadas, forçando os sujeitos a complexificar a representação que fazem da comunicação verbal (oral ou escrita).

O fato de os novos letramentos digitais constituírem-se em lugares em que as relações sociais são potencializadas nos convida a coparticipar da vida de pessoas que não conhecemos, as quais desarticulam nossas concepções de mundo e ideologias, e que multiplicam os discursos a que temos acesso de forma ilimitada (MOITA LOPES, 2010).

Após a exposição de alguns elementos teórico-conceituais na concepção dialógica da linguagem, a seguir, são apresentados os aspectos metodológicos imbricados na presente pesquisa.

\section{Percurso metodológico}

Com relação ao gênero discursivo comentário online, observa-se que, embora não tenha se constituído virtualmente, o espaço digital possibilitou um uso mais intenso e frequente. O comentário é um tipo de resposta a uma publicação, ou seja, uma réplica que pode se dirigir à própria publicação ou a outros comentários. Os comentários não exigem uma sequência cronológica para réplica e tréplica, pois o comentador pode responder a qualquer um dos comentários na ordem em que julgar adequada (Eliane Pereira SANTOS; Francisco ALVES FILHO, 2014).

O gênero comentário online tornou-se comum em portais de notícias e em redes sociais, por se constituir em um espaço interlocutivo, aberto ao leitor/interlocutor para expressar posicionamentos. Por possibilitar a contrapalavra (discurso-resposta), o estilo dessa interação sociodiscursiva segue a subjetividade dos sujeitos que ali interagem, isto é, os comentários suscitam atitudes responsivas e axiológicas de apoio, refutação, desabafo, indignação, entre outras.

Quanto ao processo de geração dos dados - entendidos como enunciados concretos ${ }^{4}$-, foram selecionados 36 comentários online (argumentativos e avaliativos) produzidos por usuários/ fãs na fanpage da rapper Karol Conka na rede social Facebook (@karolconka) - que possui em média 782.000 seguidores -, a partir de três postagens realizadas pela artista, nos dias 08, 09 e 10 de junho de 2017, como forma de divulgação do videoclipe da música Lalá.

A geração dos dados foi realizada por meio do aplicativo Netvizz (Berhnard RIEDER, 2017), cuja função é "permitir que pesquisadores exportem dados em formatos padrão de arquivos das diferentes seções da rede social Facebook" (RIEDER, 2013, p. 1 [tradução nossa]). Assim, a ferramenta permite que dados de fanpages, grupos e comunidades possam ser quantitativa e qualitativamente analisados com relação às suas características demográficas, pós-demográficas e relacionais (RIEDER, 2013).

Como mencionado anteriormente, o lançamento do videoclipe em questão gerou certa comoção não só em razão da temática considerada tabu, mas também pelas escolhas na composição da estética visual, pelas performances e posicionamentos mobilizados pela artista, tornando a fanpage lócus de discursivizações díspares, sobretudo, a respeito de questões inerentes à sexualidade e ao empoderamento feminino na contemporaneidade.

Desse modo, essas escolhas se deram não somente em virtude da movimentação gerada no interior da fanpage, mas também pela grande repercussão gerada para além da rede social, que mobilizou a atenção das pessoas em outras mídias digitais. As fanpages utilizam em sua composição a hibridização de recursos multissemióticos, isto é, a congregação da linguagem escrita com a imagem, o som e o movimento, propiciando, ainda, a interatividade e participação ativa do usuário/navegador. Em outros termos, os encontros e os espaços conversacionais e de interação com outros indivíduos são feitos multimodalmente nas telas digitais, a fim de apresentar (ou representar) a identidade projetada para aquele momento, conforme os recursos disponibilizados pela plataforma. Destarte, os sujeitos que acessam tais conteúdos podem interagir nos hipertextos e hiperlinks, curti-los, comentá-los e compartilhá-los.

Na próxima seção, é apresentada a análise empreendida dos dados gerados.

\section{A arena discursiva em @karolconka}

Como já comentado, no dia 8 de junho de 2017, a rapper Karol Conka lançou oficialmente, por meio de uma postagem em sua fanpage no Facebook, o videoclipe de seu single intitulado Lalá. Essa publicação multissemiótica - composta por texto verbal (escrito), vídeo (apenas o trecho

\footnotetext{
${ }^{4}$ Os enunciados (postagens e comentários) são apresentados conforme publicados na fanpage, portanto, sem correção, tendo como edição somente a supressão de determinadas partes e a interpolação de caracteres. No decorrer da análise, usa-se $\mathrm{P}$ para apontar a postagem que deu origem ao enunciado de comentário e $\mathrm{C}$ para remeter ao comentário em análise, além de números para auxiliar na identificação e na quantificação. Para a indicação genérica dos temas (apenas para fins de melhor visualização e organização, uma vez que eles se entrecruzam nas enunciações), utilizam-se as seguintes letras: I (Identidade), S (Sexualidade) e F (Feminismo). Para os comentários depreciativos, raivosos ou com críticas sem polidez, usou-se a letra D.
} 
inicial do clipe) e hiperlinks (as hashtags \#Lalá e \#MeLambeLá, além do link para o clipe completo hospedado no YouTube) -, a artista explica a intencionalidade da criação da música e as ideias que permearam a composição do clipe, conforme o excerto apresentado na sequência:

[P1] O clipe de \#Lalá está no ar! Escrevi essa música na intenção de informar as pessoas da necessidade da prática e da técnica do sexo oral na mulher. Tive a ideia de fazer um clipe com uma equipe toda formada por mulheres de forte posicionamento. Tivemos ideias coletivas que mostram o universo feminino de uma maneira doce e ao mesmo tempo divertida. A intenção é passar a mensagem quebrando o tabu de maneira informativa e criativa! [...] \#MeLambeLá[sic] (CONKA, 2017).

O videoclipe em questão exibe homens realizando movimentos com a língua e toques com os dedos em frutas e flores besuntadas com mel. A letra da música aborda a falta de habilidade - ou de interesse - pelo prazer sexual da mulher. Percebeu-se que determinados trechos e expressões da letra impactam as pessoas com mais veemência, visto que configuram dentre os mais replicados e referenciados nos comentários online, tais como: "Mal sabe a diferença de um clitóris pra um ovário", "Quero ser bem atendida", "O que me anima é a habilidade na lambida / Malícia, muita saliva enquanto eu queimo uma sativa", "Isso daqui não tá de enfeite", "Curvem-se, encostem os lábios na flor" e "Quebra esse tabu, isso não é nenhum favor".

No dia seguinte (09 de junho), a cantora realizou uma nova postagem, mais direcionada ao público masculino:

[P2] Bom dia pra vc que sabe fazer um \#Lalá e pra vc que recebe. E bom dia pra vc que ficou com a masculinidade ofendida porque eu disse umas verdades sobre a falta de prática lá embaixo. ASSISTAM MEU NOVO CLIPE \#Lalá: http://bit.ly/clipelala \#MeLambelá [sic] (CONKA, 2017).

Após a publicação dessa postagem, houve um aumento na repercussão do clipe nas redes, assim como maior reação dos internautas em torno de \#Lalá e \#MeLambelá. Muitas pessoas que se sentiram ofendidas com a abordagem de Karol reagiram e passaram a avaliar negativamente tanto o videoclipe na plataforma do YouTube, quanto as postagens posteriores realizadas no Facebook e em outras redes sociais.

Com base nos comentários postados, observou-se que, mesmo tendo o apoio de muitos fãs, seguidores e simpatizantes do seu trabalho, a artista foi hostilizada por muitos 'homens' e criticada por fazer referência apenas a homens, deixando de lado o fato de haver a cunilíngua também entre mulheres, uma vez que ela sempre se posicionou em favor das causas dos movimentos sociais LGBTI.

Dois dias após o lançamento (10 de junho), o videoclipe atingiu a marca de 1 milhão de visualizações. Além de 17 mil reações negativas (deslikes), o clipe recebeu cerca de 11 mil denúncias reportando presença de conteúdo sexual, o que levou o YouTube Brasil a censurá-lo como inadequado a menores de 18 anos, exigindo dos internautas a confirmação, por meio de login e senha, para efetivação do acesso, o que gerou revolta entre os fãs da cantora. Em contrapartida aos deslikes e aos discursos repulsivos, Karol Conka publicou a seguinte postagem (contrarresposta):

[P3] Lancei meu clipe há 2 dias e já atingimos a marca de 1 MILHÃO de visualizações! Tudo isso porque eu mostro flores e frutas [...] Gente tô indo ali comprar um sapato novo porque a sola do meu tá gasta de tanto pisar na opinião de gente ignorante. Ah! Vou aproveitar pra comprar um maiô também pra nadar nas lágrimas dos machistas que estão ofendidos porque eu falei umas verdades. Antes de chorar vai aprender a fazer um \#Lalá! [...] \#MeLambeLá [sic] (CONKA, 2017).

Assim, uma vez detalhados o contexto e as condições de produção dos enunciados, procede-se ao recorte do corpus para análise. De acordo com os dados recuperados por meio do Netvizz, as três postagens de Karol Conka receberam, ao todo, 1501 comentários online, dos quais 845 para a postagem 1 (P1), 396 para a postagem 2 ( $P 2$ ) e 260 para a postagem 3 (P3). A ferramenta havia contabilizado um total de 1595 comentários, contudo, recuperou 1501, ou seja, 94 comentários podem ter sido apagados (posteriormente à data de publicação) pelo administrador da fanpage e/ou pelo próprio publicador. Apenas 16 'comentários' (respostas) referem-se a imagens fixas ou animadas (gifs) e 29 são compostos por sequências de caracteres tipográficos que geram uma animação (emoticons/smileys symbo/s). Muitos 'comentários' apresentaram somente o nome de um usuário (por meio de hiperlink), em que o comentário serve, na verdade, para indicar a publicação para a pessoa referida, mediante citação de seu nome nos comentários. Dos 1501 comentários, 1086 remetem diretamente às postagens e 415 são comentários sobre comentários já feitos. Mesmo assim, verificou-se certa regularidade no estilo dos comentários, confirmando-os como gênero comentário online, uma vez que replicam as postagens de origem (P1, P2 e P3).

Os enunciados do gênero comentário online (C) são apresentados nos Quadros 1 (apreciativos: I, S e F) e 2 (depreciativos: D), gerados como reação-resposta às três postagens de Conka (P) que tematizam (ou que discursivizam/performatizam sobre) identidade, sexualidade e feminismo. 
Quadro 1 - Comentários online apreciativos relacionados às postagens de Karol Conka

\begin{tabular}{|c|c|c|c|c|c|c|}
\hline & \multicolumn{2}{|r|}{ P1 } & \multicolumn{2}{|r|}{ P2 } & \multicolumn{2}{|r|}{ P3 } \\
\hline I & $\mathrm{Cl}$ & $\begin{array}{l}\text { Mulher, vocẻ DESTROI } \\
\text { em cada nova apariçä́o } \\
\text { (videográfica) que tenho } \\
\text { o prazer de contemplar. } \\
\text { o mundo é nosso, mas } \\
\text { você é a rainha } \\
\text { Mamacita, pegue seu } \\
\text { lugar de direito. }\end{array}$ & $\mathrm{Cl}$ & $\begin{array}{l}\text { Cara... Como eu amo essa } \\
\text { mulher! Já tava na hora de } \\
\text { alguém fazer uma música } \\
\text { assim... }\end{array}$ & $\mathrm{C} 1$ & $\begin{array}{l}\text { Parabéns Karol, por falar } \\
\text { de um assunto que faz } \\
\text { parte da vida de muitas } \\
\text { mulheres. [...], tenho a } \\
\text { mesma opinião que a sua, } \\
\text { direitos são iguais. }\end{array}$ \\
\hline I & $\mathrm{C} 2$ & $\begin{array}{lr}\text { Que alegria } & \text { ser } \\
\text { contemporânea a voce } \\
\text { mulher! }\end{array}$ & $\mathrm{C} 2$ & $\begin{array}{l}\text { Nunca me identifiquei tanto } \\
\text { com uma música }\end{array}$ & $\mathrm{C} 2$ & $\begin{array}{l}\text { Orgulho dessa mulher } \\
\text { maravilhosa!!! Pisa mais } \\
\text { que tá pouco!!! }\end{array}$ \\
\hline I & C3 & $\begin{array}{l}\text { Desconstruindo padrōes, } \\
\text { seu clipe é extremamente } \\
\text { mara! Tombou. }\end{array}$ & C3 & $\begin{array}{l}\text { [...] Como diz uma amiga, a } \\
\text { intemet é um menino de } 10 \\
\text { anos que ñ está preparado } \\
\text { pra semi-nude. [...] }\end{array}$ & C3 & $\begin{array}{l}\text { Diva lacradora. Minha } \\
\text { inspiração, a voz de todas } \\
\text { as mulheres. Macharada } \\
\text { aprende a fazer \#lala de } \\
\text { respeito. }\end{array}$ \\
\hline S & $\mathrm{C4}$ & $\begin{array}{l}\text { [...] sabe Karol, vivemos } \\
\text { num país em que falar em } \\
\text { sexo é considerado } \\
\text { vulgar, só que penso que } \\
\text { é cultural e muito } \\
\text { importante. }\end{array}$ & $\mathrm{C} 4$ & $\begin{array}{l}\text { Juntas vamos quebrar esse } \\
\text { tabu, que é o sexo oral na } \\
\text { mulher. E enquanto a esses } \\
\text { machistas, que mal sabem a } \\
\text { diferença de um clitóris pra } \\
\text { um ovário, falem menos, } \\
\text { lambam mais! }\end{array}$ & $\mathrm{C} 4$ & $\begin{array}{l}\text { Estamos acostumados a } \\
\text { ver os bomens cantando } \\
\text { sobre sexo [...], mas } \\
\text { quando vemos uma mulher } \\
\text { reivindicando mais } \\
\text { dedicação na hora do } \\
\text { prazer, nós ficamos em } \\
\text { choque [...]. }\end{array}$ \\
\hline $\mathbf{S}$ & C5 & $\begin{array}{l}\text { Não acredito que a Karol } \\
\text { Conka inventou o sexo } \\
\text { oral! }\end{array}$ & $\mathrm{C5}$ & $\begin{array}{l}\text { Além de não chuparem } \\
\text { direito ainda se manifestam } \\
\text { pra passar vergonha... } \\
\text { hahahahahah }\end{array}$ & C5 & $\begin{array}{l}\text { Revolução sexual para a } \\
\text { mulherada!!! }\end{array}$ \\
\hline $\mathrm{S}$ & C6 & $\begin{array}{l}\text { Como é importante } \\
\text { receber um \#Lalá de } \\
\text { qualidade }\end{array}$ & C6 & $\begin{array}{l}\text { Eles tem que se esforçar } \\
\text { mesmo para nos agradar da } \\
\text { mesma forma que nos } \\
\text { empenhamos para agrada- } \\
\text { los }\end{array}$ & C6 & $\begin{array}{l}\text { Vagina de mulher não é } \\
\text { selo, que o cara dá uma } \\
\text { lambida que cola. Não } \\
\text { cola mais essa falta de } \\
\text { habilidade sexual dos } \\
\text { caras. }\end{array}$ \\
\hline F & C7 & $\begin{array}{l}\text { Amei o clipe e a letra, } \\
\text { muito subversiva e } \\
\text { empoderada! Foda. }\end{array}$ & C7 & $\begin{array}{l}\text { Ela é aula de feminismo. Em } \\
\text { terra de Hmeupauteama a } \\
\text { boca faz \#lálá. }\end{array}$ & C7 & $\begin{array}{l}\text { Verdades doem. Até } \\
\text { porque foram acostumados } \\
\text { a ter do lado uma submissa } \\
\text { e não uma questionadora! }\end{array}$ \\
\hline $\mathbf{F}$ & $\mathrm{C8}$ & $\begin{array}{l}\text { É Dona Karol Conka } \\
\text { infinitas palmas para a } \\
\text { senhorita! Vamos ver se } \\
\text { eles compreendem } \\
\text { direitinho! Meu respeito } \\
\text { a voce, que tem } \\
\text { contribuido infinitamente } \\
\text { ao feminismo! }\end{array}$ & C8 & $\begin{array}{l}\text { [...] Me poupe, todos os dias } \\
\text { as letras de funk colocam as } \\
\text { mulheres como algo } \\
\text { comestivel, um produto e } \\
\text { ninguém reclama... Os } \\
\text { machistas enlouquecem com } \\
\text { essa letra cheia de verdades } \\
\text { e o melhor... sem palavras } \\
\text { de baixo calão. }\end{array}$ & $\mathrm{C} 8$ & $\begin{array}{l}\text { [...] Deve doer nunca ter } \\
\text { tido ninguém pra falar pro } \\
\text { cara que ele é ruim de } \\
\text { esquema e ai de repente } \\
\text { chega uma negra } \\
\text { maravilhosa, lacradora } \\
\text { feminista [...] e diz pra ele } \\
\text { que ele não sabe fazer um } \\
\text { Lala! }\end{array}$ \\
\hline $\mathbf{F}$ & $\mathrm{Cg}$ & $\begin{array}{l}\text { Só cantou verdades com } \\
\text { essa nova música. Muitos } \\
\text { homens ficaram com a } \\
\text { masculinidade ofendida, } \\
\text { mas tinha que ser dito. } \\
\text { Nossas necessidades } \\
\text { seräo cantadas. }\end{array}$ & C9 & $\begin{array}{l}\text { [...] É disso que estamos } \\
\text { falando, acabe com o tabu, } \\
\text { chega de subestimar o sexo } \\
\text { feminino pelo Rap, hip hop } \\
\text { ou estas rimas [...] que nào } \\
\text { representam a atitude de } \\
\text { uma mulher! }\end{array}$ & $\mathrm{CP}$ & $\begin{array}{l}\text { [...] só acho que serve pra } \\
\text { muita sapatão que paga de } \\
\text { ativa [...] }\end{array}$ \\
\hline
\end{tabular}

Fonte: Conka (2017). Elaboração própria.

\#PraTodoMundoVer $O$ Quadro 1 possui quatro colunas - a primeira destinada à indicação da tipologia de comentário (I para Identidade, $\mathrm{S}$ para Sexualidade e $\mathrm{F}$ para Feminismo) e as três últimas relativas às três postagens ( $\mathrm{P1}, \mathrm{P} 2$ e P3) realizadas por Karol Conka, contendo subdivisões referentes aos comentaristas (C1 até C9) - e nove linhas em que são expressos os comentários online propriamente ditos. 
Quadro 2 - Comentários online depreciativos relacionados às postagens de Karol Conka

\begin{tabular}{|c|c|c|c|c|c|c|}
\hline & \multicolumn{2}{|r|}{ P1 } & \multicolumn{2}{|r|}{$\mathbf{P 2}$} & \multicolumn{2}{|r|}{ P3 } \\
\hline D & $\mathrm{C} 10$ & $\begin{array}{l}\text { Cantora ou sexóloga? } \\
\text { Mulher ou feminista? } \\
\text { Achar que precisa dizer } \\
\text { ao mundo como se faz } \\
\text { as coisas! }\end{array}$ & C10 & $\begin{array}{l}\text { Respeito } \\
\text { posicionamento pessoal, } \\
\text { politico e feminista desta } \\
\text { moça, mas me desculpem } \\
\text { acho a música dela uma } \\
\text { porcaria. }\end{array}$ & $\mathrm{Cl0}$ & $\begin{array}{l}\text { Que putaria! Um clipe } \\
\text { com cenas explicitas de } \\
\text { apologias ao sexo, que } \\
\text { nojo. }\end{array}$ \\
\hline D & C11 & $\begin{array}{l}\text { Nossa, que clipe mais } \\
\text { indecente e } \\
\text { desnecessairio. Falar de } \\
\text { sexo assim já é fim de } \\
\text { carreira, falar de sexo } \\
\text { com drogas pior ainda } \\
\text { [..] }\end{array}$ & C11 & $\begin{array}{l}\text { Até gostava dela, mas } \\
\text { acho que dessa vez ela } \\
\text { apelou. A letra da música } \\
\text { e o clipe são muito } \\
\text { apelativos, apresentam um } \\
\text { conteúdo sexual explicito. } \\
\text { As mulheres precisam se } \\
\text { dar o respeito antes de } \\
\text { exigir o mesmo dos } \\
\text { homens? }\end{array}$ & C11 & $\begin{array}{l}\text { Falando da inabilidade } \\
\text { de caras com sexo oral, } \\
\text { kkkkk, olha o nivel. } \\
\text { Estão acabando com a } \\
\text { cultura e com a música } \\
\text { brasileira... olha o tipo } \\
\text { de "diva" que querem } \\
\text { fabricar?! }\end{array}$ \\
\hline D & $\mathrm{C} 12$ & $\begin{array}{l}\text { Marra logo se entende: } \\
\text { feminista que tem } \\
\text { opinião forte e não } \\
\text { aceita outras ideias com } \\
\text { facilidade }\end{array}$ & $\mathrm{C} 12$ & $\begin{array}{l}\text { O problema de algumas } \\
\text { feministas é achar que } \\
\text { precisa esculhambar os } \\
\text { homens, falar como se } \\
\text { fossem seres superiores. } \\
\text { Não tem como querer } \\
\text { igualdade, sendo desigual. }\end{array}$ & $\mathrm{C} 12$ & $\begin{array}{l}\text { Sou mulher, a favor do } \\
\text { empoderamento } \\
\text { feminino, mas essa moça } \\
\text { é RUIM DEMAIS. Me } \\
\text { desculpem os fäs, é só } \\
\text { minha opinião. Existem } \\
\text { muitas mulheres } \\
\text { competentes na música e } \\
\text { nas artes que } \\
\text { representarn muito mais } \\
\text { a força e o valor das } \\
\text { mulheres. }\end{array}$ \\
\hline
\end{tabular}

Fonte: Conka (2017). Elaboração própria.

\#PraTodoMundoVer $O$ Quadro 2 possui quatro colunas - a primeira destinada à indicação dos comentários depreciativos (D) e as três últimas relativas às três postagens (P1, P2 e P3) realizadas por Karol Conka, contendo subdivisões referentes aos comentaristas $(C 10, C 11$ e C12) - e três linhas em que são expressos os comentários online propriamente ditos.

Referente aos comentários às postagens geradoras, optou-se em separá-los em categorias nos Quadros 1 e 2 por questões didáticas para visualização e organização, justamente em virtude dos grandes temas elencados para a pesquisa (identidade, sexualidade e feminismo). No entanto, percebeu-se que tal arbitrariedade não pode ser totalmente considerada para fins de análise, uma vez que, em virtude da confluência das temáticas, vários comentaristas acabam por mesclálos em uma mesma composição, o que é, aliás, próprio do gênero comentário. Provavelmente, essa mescla nos comentários também se dê em função da multissemioticidade presente nas postagens, uma vez que ela é composta por múltiplas linguagens, para além do signo verbal, o que influencia nos processos de recepção, compreensão, significação e reenunciação de cada interlocutor, que normalmente se expressará de forma verbal escrita (conforme observado, apenas 45 respostas não eram compostas por texto verbal escrito).

Analisando os enunciados pela ótica da historicidade, significa dizer que eles estão ligados dialogicamente a outros enunciados, visto que, conforme Bakhtin (2011), "não pode haver enunciado isolado. Ele sempre pressupõe enunciados que o antecedem e o sucedem. [...]. Ele é apenas o elo na cadeia e fora dessa cadeia não pode ser estudado" (p. 371). Os enunciados se compõem da dimensão extraverbal e da dimensão verbal-semiótica, assim como se relacionam à expressão material, a qual resulta da interação de três participantes: o locutor (autor, escritor/ falante), o interlocutor (leitor, espectador, ouvinte) e o tópico (tema).

Considerando que o autor de um enunciado é aquele que se responsabiliza pelo seu dizer/ escrever, a autoria no gênero comentário online é deveras complicada para ser identificada, pois, por mais que o sujeito acesse a fanpage por meio de um apelido (nickname) - muitas vezes com foto -, este pode ser um perfil social falso, com o intuito de mascarar a identidade empírica deste enunciador, que, justamente por conta do ocultamento, pode assumir tons mais incisivos, agressivos 
e combativos em suas enunciações - conforme evidenciam os enunciados elencados nas categorias C10D, C11D e C12D (Quadro 2) -, muitas vezes agindo contra os princípios éticos, morais e legais vigentes em determinado contexto social.

Outra dificuldade encontra-se na impossibilidade de acesso aos dados completos de alguns perfis, em virtude das configurações de privacidade estipuladas pelo usuário sobre quem pode acessá-los, ou, ainda, quando da incompletude dos dados disponibilizados. A marca de gênero é observada nos modos de enunciar e caracteriza-se como performance, uma vez que os sujeitos assinam os enunciados e argumentam/contra-argumentam a respeito das temáticas em voga, posicionando-se. Visto que a compreensão consiste na contraposição do discurso do outro ao discurso do interlocutor, isto é, a construção do sentido advém do diálogo entre locutor e interlocutor, em que ambos desempenham papel ativo, percebe-se em alguns comentários essa interlocução:

[P2C4S] "Juntas vamos quebrar esse tabu, que é o sexo oral na mulher [...]" [grifos nossos].

[P1C1I] "[...] O mundo é nosso, mas você é a rainha Mamacita [...]" [grifos nossos].

[P2C9F] "[...] É disso que estamos falando, acabe com o tabu [...]" [grifos nossos].

Nesse processo interacional, o leitor (interlocutor) é compreendido como dotado de responsividade ativa, pois é a sua resposta que permite que se materialize o entendimento do dizer e do dito do autor (locutor). A própria posição autor, isto é, a capacidade de encontrar uma "segunda voz" (BAKHTIN, 2011) no coro discursivo que é a comunicação humana, "está estritamente ligada ao conceito da agência nos movimentos coletivos, para ressaltar o fato de que, quando os indivíduos se engajam em ações sociais para a transformação, eles se vêem a si mesmos como coautores" (Angela B. KLEIMAN, 2006, p. 85).

A análise dos comentários também apontou com regularidade a recorrência de certas escolhas lexicais peculiares ao universo LGBTI - muitas delas acionadas pela cultura hip-hopper/ rapper e pelos adeptos ao feminismo -, tais como hino (90 ocorrências), lacre/lacrou/lacradora (68), tiro (53), pisa/pisar/pisando (45), arraso/arrasar (39), tombar/tombo/tombamento (31), sambar na cara (6), entre outras.

Percebe-se que esse léxico, frequentemente usado por Karol Conka em suas postagens, é reutilizado em comentários de apoio à artista, consistindo, portanto, em um revozeamento de discursos anteriores, em que os sujeitos não somente reproduzem os discursos de Karol, mas acrescentam estes às suas enunciações, produzindo sentidos diferentes das primeiras enunciações. Evidencia-se a presença do "discurso interiormente persuasivo" (BAKHTIN, 2015, p. 136), em que o conjunto de palavras utilizadas por Karol em determinadas circunstâncias soma-se às palavras dos seus interlocutores criando novos discursos, pois a "estrutura semântica do discurso interiormente persuasivo não é concluída, é aberta, e em cada novo contexto dialogante é capaz de revelar possibilidades semânticas novas" (BAKHTIN, 2015, p. 140). Por mais que essa escolha lexical demarque o pertencimento desses sujeitos ao(s) referido(s) grupo(s) identitário(s), é evidente que também pode ser utilizada por aqueles que não se enquadram nesses agrupamentos, sobretudo, aos que intencionam zombar ou contrapor os posicionamentos da artista por meio da reenunciação depreciativa dessas gírias.

De acordo com Bakhtin (2015), a palavra só adquire vida em seu direcionamento para o objeto e não possui sentido nela mesma, sendo dotada de significado somente se for considerado o outro para o qual ela é direcionada e a dimensão social que a permeia. Consequentemente, em nenhum momento o discurso é impessoal e neutro, ele sempre é dito por alguém e em determinada situação, carregado de intencionalidade. "[...] o contexto que moldura o discurso do outro cria um fundo dialogante cuja influência pode ser muito grande" (BAKHTIN, 2015, p. 132).

Dessa forma, para além dos aspectos verbais do enunciado - a seleção lexical, a disposição das palavras na frase e a entonação (a expressão sonora da valoração social) -, os elementos extraverbais (subentendidos) - o horizonte valorativo (na situação de interação), o horizonte temático (o objeto de que o enunciado está falando) e o horizonte espaço-temporal (onde/quando) (Valentin Nikolaevich VOLOCHÍNOV, 2013) - possibilitam a compreensão do sentido da forma deste enunciado.

Quanto à expressividade dos comentários veiculados aos conteúdos temáticos (identidade, sexualidade e feminismo) propriamente ditos, têm-se as seguintes constatações: a) Identidade:

Uma investigação dos processos identitários envolve considerá-los a partir de configurações de identidades construídas por processos de trocas intersubjetivas ou, como diria Bakhtin (2011), a partir da alteridade, ou seja, a partir de seu lugar privilegiado externo ao eu, um lugar "excedente de visão". James Paul Gee (2000-2001) atenta para a questão da movência das identidades, em que o 'tipo de pessoa' que é reconhecido como um 'ser', em um determinado tempo e lugar, pode mudar de momento a momento na interação, pode mudar de contexto para contexto e, é claro, pode ser ambígua ou instável. 
Como as identidades são construídas em um processo contínuo de avaliação e validação que ocorre nas relações entre os sujeitos no âmago das interações sociais (BAKHTIN, 2011), elas não podem ser concebidas a partir das particularidades dos sujeitos de forma isolada, mas como uma construção histórica e social que é contínua, movediça e contrastante. Depreende-se, portanto, que as identidades estão intimamente relacionadas às práticas discursivas dos sujeitos.

Volochínov (2013) pontua que é importante que o auditório social (os interlocutores) ao qual o enunciado está direcionado tenha valorações (ou posições) compartilhadas, para que a entonação tenha o sentido almejado, pois é ela que norteia a escolha das palavras e o arranjo que elas terão na forma da enunciação. Como todo enunciado é dialógico, é essencial considerar a sua orientação social, isto é, quem diz, o que diz e para quem diz. Nesse sentido, a atitude dos interlocutores perante o objeto e a situação em si denota a reafirmação de "identidades por afinidade" (GEE, 2000-2001), conforme se percebe nos comentários a seguir (sobretudo, nos destaques nossos):

[P3C1I] Parabéns Karol, por falar de um assunto que faz parte da vida de muitas mulheres [...], tenho a mesma opinião que a sua, direitos são iguais.

[P3C3I] Diva lacradora. Minha inspiração, a voz de todas as mulheres. Macharada aprende a fazer \#lala de respeito.

[P1C2I] Que alegria ser contemporânea a você mulher!

[P1C3I] Mulher, você DESTROI em cada nova aparição (videográfica) que tenho o prazer de contemplar. O mundo é nosso, mas você é a rainha Mamacita, pegue seu lugar de direito.

No tocante à identidade, "há uma relação dialética entre a representação individual de si mesmo e a representação que os outros têm do indivíduo, o que determina a reciprocidade na constituição de um e do outro" (KLEIMAN, 2006, p. 79). Nessa perspectiva, pode-se dizer que "a identidade é uma construção, um efeito, um processo de produção, uma relação, um ato performativo" (Tomaz Tadeu da SILVA, 2014, p. 96), ou seja, é compreendida como efeito discursivo, não preexistindo ao discurso, apontando para o que é em performance (Judith BUTLER, 1997; MOITA LOPES, 2013b).

Os sujeitos que não se identificam com a performatividade de Karol Conka - como cantora/ artista ou como ícone do feminismo na sociedade atual - também se manifestaram, apresentando contrapalavra depreciativa e vozes de resistência:

[P1C10D] [...] Mulher ou feminista? Achar que precisa dizer ao mundo como se faz as coisas! [grifos nossos]

[P2C10D] "Respeito o posicionamento pessoal, político e feminista desta moça, mas me desculpem acho a música dela uma porcaria [grifos nossos].

[P2C11D] Até gostava dela, mas acho que dessa vez ela apelou. [...] [grifos nossos].

[P3C11D] [...] Estão acabando com a cultura e com a música brasileira... olha o tipo de "diva" que querem fabricar?! [grifos nossos].

[P3C 12D] [...] Existem muitas mulheres competentes na música e nas artes que representam muito mais a força e o valor das mulheres [grifos nossos].

b) Sexualidade:

Na contemporaneidade, as redes sociais da Internet constituem-se em espaços profícuos para que os discursos e seus acentos de valor se imponham e se transmitam de forma tensa e dialógica. Ao tratar da sexualidade em sua fanpage, mais especificamente sobre a cunilíngua e o prazer sexual feminino, Conka oportunizou às mulheres o debate sobre esses assuntos que ainda são considerados tabus no século XXI, enquanto a abordagem sobre sexo oral masculino é comum e rotineiro na sociedade brasileira, sobretudo em letras de músicas do estilo funk escritas por homens, por exemplo. Por meio do comentário [P2C7F], constata-se o interdiscurso feito ao refrão da música Deu onda (versão explícita) do funkeiro MC G15: "[...] Em terra de \#meupauteama a boca faz \#lálá".

Mesmo com a desconstrução e da superação de certas normas, mitos e tabus em relação à sexualidade na atualidade, constata-se que o corpo feminino foi censurado por tanto tempo que nem as próprias mulheres o conhecem direito. De acordo com a pesquisa sobre sexualidades femininas e prazer sexual realizada por Olga Regina Zigelli Garcia (2007), as falas das mulheres indicam que, mesmo com as conquistas feministas na contemporaneidade, perduram as assimetrias de gênero, na medida em que o exercício da sexualidade ainda é permeado por conflitos originados nas questões relativas às construções de gênero, à identidade, à falta de conhecimento sobre o corpo e à visão heteronormativa incapaz de transcender os dualismos.

Nessa perspectiva, os comentários evidenciam conteúdos que reenunciam e reenquadram (ampliam) a importância da realização da cunilíngua, ou, mesmo, da discursivização das 
necessidades sexuais femininas, reforçando os três discursos de origem pautados em \#Lalá e \#MelambeLá:

[P1C5S] Não acredito que a Karol Conka inventou o sexo oral!

[P1C6S] Como é importante receber um \#Lalá de qualidade.

[P2C6S] Eles tem que se esforçar mesmo para nos agradar da mesma forma que nós mulheres nos empenhamos para agrada-los.

[P3C6S] Vagina de mulher não é selo, que o cara dá uma lambida que cola. Não cola mais essa falta de habilidade sexual dos caras.

[P1C4S] [...] sabe Karol, vivemos num país em que falar em sexo é considerado vulgar, só que penso que é cultural e muito importante.

[P3C4S] [...] estamos acostumados a ver os homens cantando sobre sexo [...], mas quando vemos uma mulher reivindicando mais dedicação na hora do prazer, nós ficamos em choque [...].

De forma geral, verifica-se que os já-ditos sobre sexualidade feminina e toda a acentuação valorativa implicada permeiam os discursos dos(as) comentaristas às postagens da artista. Diante das discussões em @karolconka em torno da prática da cunilíngua, percebe-se que falar abertamente sobre as temáticas sexuais antes silenciadas ou restritas aos ambientes íntimos tornouse prática comum na contemporaneidade. Os discurso-respostas, apresentados clara e explicitamente, emanam essa quebra da interdição à abordagem da prática do sexo oral feminino. Entretanto, observou-se, em menor grau, a presença de vozes dissonantes de cunho sexista, que se mostram resistentes e/ou reforçam um conservadorismo social já existente, com vistas a desestabilizar os discursos apreciativos reenunciados e a deslegitimar a posição discursiva da cantora como defensora (e promotora) do prazer sexual feminino. Os comentários a seguir evidenciam contrapalavras ao que Conka havia pronunciado em sua fanpage:

[P1C10D] Cantora ou sexóloga? [...].

[P1C11D] [...] Falar de sexo assim já é fim de carreira [...].

[P3C11D] [...] Falando da inabilidade de caras com sexo oral, kkkkk, olha o nível [...].

[P3C10D] [...] cenas explícitas de apologias ao sexo, que nojo.

Não é possível saber o sexo/gênero dos comentadores online, contudo, pressupõe-se que essa problemática em torno do tema deriva do imaginário machista que idealiza a mulher somente como objeto de prazer do homem. Assim, consideram que Conka não estaria legitimada a discursar sobre sexo ou a ter suas expectativas de prazer atendidas. Afinal, conforme explica Butler (2013), "o 'sexo' é um ideal regulatório cuja materialização é imposta: esta materialização ocorre (ou deixa de ocorrer) através de certas práticas altamente reguladas. [...] o 'sexo' é um construto ideal que é forçosamente materializado através do tempo" (p. 154).

Entretanto, por meio dos seus discurso-respostas subversivos, Conka reposiciona a si e as suas interlocutoras como protagonistas do próprio prazer, sem pudores ao dizer "umas verdades sobre a falta de prática lá embaixo" ou a respeito dos "meninos mimados que antes de chorar deveriam aprender a fazer um Lalá", revozeando e potencializando os já-ditos pela letra do clipe em questão: "[...] Dedilham ao contrário / Egoístas criando um orgasmo imaginário [...] / Pouco importa pra ele se você também tá satisfeita [...] / Quero ser bem atendida [...] / Lá lá lá, me lambe lá [...] / Minhas amigas concordam também [...]" (CONKA, 2017).

Diante do exposto, compreende-se que, nesses sites de redes sociais capitaneados por influenciadores(as) digitais devidamente engajados(as), se constituem arenas discursivas que possibilitam aos sujeitos não só se manifestarem sobre sua sexualidade e práticas sexuais, mas também construir, modificar ou performatizar suas identidades no espaço público.

c) Feminismo:

Várias gerações de mulheres foram marcadas, física e mentalmente, pela opressão. De acordo com Luciana Maria de Aragão Ballestrin (2017), é fundamental a criação de novos fóruns, encontros e diálogos de luta feminista, de espaços alternativos (principalmente no ambiente virtual) de colaboração que não debatam apenas sobre as diferenças, mas, sim, sobre estar em diferentes posições para enxergá-las.

Com base no exposto, são apresentados a seguir alguns enunciados que, ao responder às postagens de Conka, materializam reenunciações/acentuações que enaltecem o posicionamento feminista da artista e avalizam o espaço de discursivização criado em sua fanpage:

[P1C9F] Só cantou verdades com essa nova música. Muitos homens ficaram com a masculinidade ofendida, mas tinha que ser dito. Nossas necessidades serão cantadas. 
[P3C8F] [...] Deve doer nunca ter tido ninguém pra falar pro cara que ele é ruim de esquema e aí de repente chega uma negra maravilhosa, lacradora feminista [...] e diz pra ele que ele não sabe fazer um Lalá!

[P1C8F] É Dona Karol Conka infinitas palmas para a senhorita! Vamos ver se eles compreendem direitinho! Meu respeito a você, que tem contribuído infinitamente ao feminismo!

[P2C8F] [...] Me poupe, todos os dias as letras de funk colocam as mulheres como algo comestível, um produto e ninguém reclama... Os machistas enlouquecem com essa letra cheia de verdades $[\ldots]$.

[P2C9F] [...] É disso que estamos falando, acabe com o tabu, chega de subestimar o sexo feminino pelo Rap, hip hop ou estas rimas [...] que não representam a atitude de uma mulher!

Pela linguagem, percebe-se que os comentários foram realizados, majoritariamente, por mulheres que encontraram, nas enunciações de Conka, abertura para verbalizar seus anseios, conforme verificado nos ditos "Só cantou verdades", "Nossas necessidades serão cantadas", "com essa letra cheia de verdades" e "tinha que ser dito". Ao enunciarem que Conka é "empoderada", "lacradora feminista" e que "tem contribuído infinitamente ao feminismo", as interlocutoras a reconhecem como feminista e elevam-na à representante desse movimento de luta, ao mesmo passo que se sentem pertencentes ao grupo. Desse modo, as identidades feministas são construídas a partir de uma relação de "alteridade" (BAKTHIN, 2011) em que o 'outro' (as comentadoras) é quem dá acabamento para esse 'eu'.

O discurso feminista mostra-se, nesse cenário, espaço de luta e de risco, marcado pela intensidade e sujeito não apenas aos jogos de poder, como também potencialmente permeado pela agressividade e pela subversão, ou seja, o espírito empreendedor para defender territórios já conquistados, assim como para quebrar determinados tabus. Isto é constatado por meio das enunciações imperativas "acabe com o tabu" e "chega de subestimar o sexo feminino", e também nos momentos em que os destinatários das mensagens são enunciados: "diz pra ele que ele não sabe fazer um Lalá!", "Muitos homens ficaram com a masculinidade ofendida", "Vamos ver se eles compreendem direitinho!", "Os machistas enlouquecem". Verifica-se ainda nos comentários [P2C8F] e [P2C9F] que as interlocutoras de Conka discursivizam pelo repúdio às letras de rap/hip-hop e de funk que normalmente veiculam mensagens machistas e misóginas, ao passo que sobrelevam a produção da artista, conforme observado explicitamente em [P1C7F]: "Amei o clipe e a letra, muito subversiva e empoderada!".

No entanto, constatou-se a presença de interlocutores que não são aliados e alinhados em suas disputas, fazendo emergir uma série de discursos já-ditos depreciativos sobre as mulheres, conforme indicam os seguintes excertos:

[P3C9F] [...] só acho que serve pra muita sapatão que paga de ativa [...].

[P3C7F] Verdades doem. Até porque foram acostumados a ter do lado uma submissa e não uma questionadora!

[P2C11D] [...] As mulheres precisam se dar o respeito antes de exigir o mesmo dos homens?

[P2C12D] [...] Não tem como querer igualdade, sendo desigual.

Nessa conjectura, Ballestrin (2017) sugere a projeção de feminismos subalternos para a compreensão de um movimento paradoxal: "a construção dos feminismos outros só é possível quando eles se subalternizam em relação ao próprio feminismo moderno" (BALLESTRIN, 2017, p. 1035). Tal como propõe Moita Lopes (2013b), tão importante como "desessencializar qualquer sentido de norma para a heterossexualidade e masculinidade, é igualmente crucial descristalizar qualquer sentido de homonormatividade e feminilidade" (p. 243-244).

Diante do exposto em relação aos enunciados (postagens e comentários), entende-se que, como sujeitos de discurso, "só podemos analisar quem somos nas interações e narrativas cotidianas situadas no aqui e no agora, traçando laços entre aspectos microssociais (na interação) e outros de natureza macrossocial" (MOITA LOPES, 2013b, p. 239).

Bakhtin (2011) aborda a questão da alteridade e da construção de sentidos a partir dos enunciados de outrem. Ele afirma que não há enunciados isolados, à medida que todo e qualquer enunciado pressupõe enunciados que o antecederam - os já-ditos - e aqueles que se sucederão no tempo e no espaço - os pré-figurados. Em outras palavras, enquanto o enunciado como evento é acabado e repetível (há um início e um fim que se marca pela alternância dos sujeitos e pela possibilidade de reação resposta-ativa), o enunciado como acontecimento é único e irrepetível.

As relações dialógicas consistem em relações pessoais, isto é, em "vínculos semânticos personificados" (BAKHTIN, 2011, p. 374). Nesse contexto de interpretação acontecem dois movimentos: o retrospectivo (que remete às experiências passadas) e o prospectivo (que antecipa as vivências futuras do leitor), em que "o texto só tem vida contatando com outro texto (contexto). Só no ponto desse contato de textos eclode a luz que ilumina retrospectiva e prospectivamente, iniciando dado texto no diálogo" (BAKHTIN, 201 1, p. 401). 
No tocante à arena discursiva constatada em @karolconka, "por constituir espaço de disputa e de luta identitária; de natureza discursiva porque, a despeito dos embates físicos ali travados, a matriz da tensão são os valores projetados sobre o evento" (MAGALHÃES; QUEIJO, 2015, p. 169), tem-se as seguintes contraposições nos comentários feitos pelos interlocutores, independentemente da relação direta entre a postagem de origem e os comentários feitos para aquela postagem:

Exemplo 1 - Identidade:

[P1] [...] Escrevi essa música na intenção de informar as pessoas da necessidade da prática e da técnica do sexo oral na mulher. Tive a ideia de fazer um clipe com uma equipe toda formada por mulheres de forte posicionamento. Tivemos ideias coletivas que mostram o universo feminino de uma maneira doce e ao mesmo tempo divertida [...] [grifos nossos].

[P1C3I] Desconstruindo padrões, seu clipe é extremamente mara! Tombou [grifos nossos].

[P2C2I] Nunca me identifiquei tanto com uma música [grifos nossos].

[P1C10D] [...] Mulher ou feminista? Achar que precisa dizer ao mundo como se faz as coisas! [...] [grifos nossos].

[P3C12D] Sou mulher, a favor do empoderamento feminino, mas essa moça é RUIM DEMAIS. Me desculpem os fãs [...] [grifos nossos].

Exemplo 2 - Sexualidade:

[P2] Bom dia pra vc que sabe fazer um \#Lalá e pra vc que recebe/ [P3] [...] Tudo isso porque eu mostro flores e frutas [...] [grifos nossos].

[P2C3I] [...] Como diz uma amiga, a internet é um menino de 10 anos que ñ está preparado pra semi-nude. [...] [grifos nossos].

[P2C8F] [...] Os machistas enlouquecem com essa letra cheia de verdades e o melhor... sem palavras de baixo calão [grifos nossos].

[P2C11D] [...] A letra da música e o clipe são muito apelativos, apresentam um conteúdo sexual explícito. [...] [grifos nossos].

Exemplo 3 - Feminismo:

[P2] [...] E bom dia pra vc que ficou com a masculinidade ofendida porque eu disse umas verdades sobre a falta de prática lá embaixo. [grifos nossos].

[P2C4S] [...] E enquanto a esses machistas, que mal sabem a diferença de um clitóris pra um ovário, falem menos, lambam mais! [grifos nossos].

[P2C5S] Além de não chuparem direito ainda se manifestam pra passar vergonha [...] [grifos nossos].

[P2C12D] O problema de algumas feministas é achar que precisa esculhambar os homens, falar como se fossem seres superiores [grifos nossos].

Por meio dos exemplos apresentados, observou-se que, na enunciação dos sujeitos, são mobilizadas forças centrífugas (as vozes que indicam a possibilidade de outras narrativas sobre os outros modos de vivenciar o prazer sexual por meio da cunilíngua, frente ao machismo e a misoginia) - e forças centrípetas (as vozes daqueles que mantêm discursos machistas e que insistem em censurar, negar e reprimir o prazer feminino por meio do sexo oral, ou que não procuram compreender ou se informar sobre o assunto). Retomando Bakhtin (2015), as forças centrífugas são aquelas que dinamizam, relativizam, desestabilizam e tornam a língua mais flexível, enquanto as centrípetas regulam, normatizam e estabilizam a língua.

A cada postagem realizada por Karol Conka, existem comentários consonantes e dissonantes, sustentados por posicionamentos valorativos (apreciativos e depreciativos), evidenciando que o caráter heterodiscursivo da língua se constitui justamente por meio dessas forças, que podem ser compreendidas como dois discursos distintos que atuam sobre a língua, configurando o enunciado em uma arena em que essas forças se encontram e se enfrentam. Portanto, além da inter-relação entre forças centrífugas e centrípetas na constituição da linguagem, Bakhtin (2015) compreende que a língua é sempre carregada de valores sobre o mundo, constitui horizontes axiológicos específicos: "como resultado do trabalho de todas essas forças estratificadoras, não permanecem na língua quaisquer palavras e formas neutras, 'de ninguém': a língua fica [...] perpassada de intenções, acentuada" (BAKHTIN, 2015, p. 69).

Em tempos de mobilidade identitária, as pessoas "vivem vidas translocais e [...] o sentido de localidade é dado no aqui e no agora do discurso (na tela de um computador, por exemplo, cujos discursos focalizados podem mudar de modo repentino, atravessando o globo [...])" (MOITA LOPES, 2013b, p. 234). 


\section{Considerações finais: 'já que é pra tombar, tombel'}

Contemporaneamente, a Web 2.0 constitui-se como um espaço-tempo de construção identitária. Tal compreensão é perceptível nos comentários escritos, nos quais os participantes de espaços de afinidades se encontram interacionalmente na construção de significados, à medida que "se envolvem na constituição de suas identidades ou performances identitárias em práticas sociais de letramentos" (MOITA LOPES, 2013 b, p. 237 [grifos do autor]).

Ao se enunciar em eventos discursivos na Web, os interlocutores estão se inserindo em atos situados de linguagem, mobilizando implicações no mundo ético. Portanto, é no "ato singular responsável" (BAKHTIN, 2010, p. 44) que a singularidade da existência de cada sujeito é reconhecida, sendo que este não tem álibi para não ocupar o seu lugar e para desconsiderar a singularidade do seu lugar, que é único.

Por meio da análise descritivo-interpretativista dos já-ditos nos comentários online referentes às postagens em torno de \#Lalá e \#MeLambelá em @karolconka foi possível observar a valoração como presença viva no uso de linguagens. Tanto nos discursos de concordância quanto nos de discordância, buscou-se ratificar a noção bakhtiniana de que a concepção do seu objeto, por parte do discurso, configura-se em ato sempre dialógico e, sobretudo, avaliativo/valorativo. Nos constantes embates entre as forças centrífugas e as forças centrípetas, a fanpage de Karol Conka no Facebook atuou na construção de representações que os sujeitos criam do mundo.

Em síntese, a análise apresentada aponta para a relevância de compreender os discursos performativos já-ditos acerca da identidade, da sexualidade e das formas de exercício do feminismo, para que se possam construir novos modos de discursivizar o empoderamento feminino na contemporaneidade, frente à era da comunicação mediada pelo computador e das redes sociais na Internet.

\section{Referências}

ARAÚJO, Júlio. "Reelaborações de gêneros em redes sociais". In: ARAÚJO, Júlio; LEFFA, Vilson (Orgs.). Redes sociais e ensino de línguas: o que temos de aprender? 1. ed. São Paulo: Parábola Editorial, 2016. p. 49-64.

BAKHTIN, Mikhail. Para uma filosofia do ato responsável. São Carlos: Pedro e João Editores, 2010.

BAKHTIN, Mikhail. Estética da criação verbal. 6. ed. São Paulo: Martins Fontes, 2011.

BAKHTIN, Mikhail. Teoria do romance I: a estilística. São Paulo: Editora 34, 2015.

BAKHTIN, Mikhail. Os gêneros do discurso. São Paulo: Editora 34, 2016.

BALLESTRIN, Luciana Maria de Aragão. "Feminismos subalternos". Revista Estudos Feministas, Florianópolis, v. 25, n. 3, p. 1035-1054, set./dez. 2017.

BOYD, Danah M.; ELLISON, Nicole B. "Social Network Sites: Definition, History, and Scholarship". Journal of Computer-Mediated Communication, Oxford, v. 13, n. 1, p. 210-230, out. 2007. Disponível em https://academic.oup.com/jcmc/article-abstract/13/1/210/4583062. https://doi.org/10.1 111 1/j.10836101.2007.00393.x. Acesso em 09/09/2019.

BRÊDA, Lucas. "É o poder”. Rolling Stone, São Paulo, mar. 2017. Disponível em http://rollingstone.uol. com.br/edicao/edicao-127/karol-conka-e-o-poder\#imagem0. Acesso em 29/12/2017.

BUTLER, Judith. Excitable speech: a politics of the performative. New York: Routledge, 1997.

BUTLER, Judith. "Corpos que pesam: sobre os limites discursivos do 'sexo'”. In: LOURO, Guacira Lopes (Org.). O corpo educado: pedagogias da sexualidade. 3. ed. Belo Horizonte: Autêntica, 2013. p. 151-172.

CONKA, Karol.@karolconka, 2017. Disponível em https://pt-br.facebook.com/karolconka/. Acesso em 22/12/2017.

GARCIA, Olga Regina Zigelli. Sexualidades femininas e prazer sexual: uma abordagem de gênero. 2007. 232f. Tese (Doutorado Interdisciplinar em Ciências Humanas) - Programa de Pós-Graduação Interdisciplinar em Ciências Humanas, Universidade Federal de Santa Catarina, Florianópolis, SC, Brasil.

GEE, James Paul. "Identity as an analytic lens for research in education". Review of Research in Education, Washington DC, v. 25, p. 99-125, 2000-2001. 
GUIMARÃES, Thayse Figueira; MOITA LOPES, Luiz Paulo da. "Entextualizações estratégicas: performances sensualizadas de raça em práticas discursivas na Web 2.0". Linguagem em (Dis)curso, Tubarão, v. 16, n. 2, p. 289-307, maio/ago. 2016.

KLEIMAN, Angela B. "Processos identitários na formação profissional: o professor como agente de letramento". In: CORRÊA, Manoel Luiz Gonçalves; BOCH, Françoise (Orgs.). Ensino de língua: representação e letramento. Campinas: Mercado de Letras, 2006. p. 75-91.

KUMARAVADIVELU, Bala. "A linguística aplicada na era da globalização". In: MOITA LOPES, Luiz Paulo da (Org.). Por uma linguística aplicada indisciplinar. 2. ed. São Paulo: Parábola Editorial, 2008. p. 129-148.

MAGALHÃES, Anderson Salvaterra; QUEIJO, Maria Elizabeth da Silva. "A arena discursiva das ruas e a condição pós-moderna: da manifestação à metacarnavalização". Bakhtiniana, São Paulo, v. 10, n. 3, p. 166-185, set./dez. 2015.

MOITA LOPES, Luiz Paulo da. "Introdução: uma linguística aplicada mestiça e ideológica: interrogando o campo como linguista aplicado". In: MOITA LOPES, Luiz Paulo da (Org.). Por uma linguística aplicada indisciplinar. 2. ed. São Paulo: Parábola Editorial, 2008. p. 13-44.

MOITA LOPES, Luiz Paulo da. "Os novos letramentos digitais como lugares de construção de ativismo político sobre sexualidade e gênero". Trabalhos em Linguística Aplicada, Campinas, v. 49, n. 2, p. 393-417, jul./dez. 2010.

MOITA LOPES, Luiz Paulo da. "Introdução. Fotografias da Linguística Aplicada brasileira na modernidade recente: contextos escolares". In: MOITA LOPES, Luiz Paulo da (Org.). Linguística Aplicada na modernidade recente: festschrift para Antonieta Celani. São Paulo: Parábola Editorial, 2013a. p. 15-37.

MOITA LOPES, Luiz Paulo da. "Gênero, sexualidade, raça em contextos de letramentos escolares". In: MOITA LOPES, Luiz Paulo da (Org.). Linguística Aplicada na modernidade recente: festschrift para Antonieta Celani. São Paulo: Parábola Editorial, 2013b. p. 225-247.

PENNYCOOK, Alastair. "Uma linguística aplicada transgressiva". In: MOITA LOPES, Luiz Paulo da (Org.). Por uma linguística aplicada indisciplinar. 2. ed. São Paulo: Parábola Editorial, 2008. p. 6784.

RAJAGOPALAN, Kanavillil. "Repensar o papel da linguística aplicada". In: MOITA LOPES, Luiz Paulo da (Org.). Por uma linguística aplicada indisciplinar. 2. ed. São Paulo: Parábola Editorial, 2008. p. 149-168.

RECUERO, Raquel. Engajamento X audiência no Facebook: uma breve discussão, 2013. Disponível em http://www.raquelrecuero.com/arquivos/2013/03/engajamento-x-audiencia-no-facebook.html. Acesso em 09/09/2019.

RIEDER, Berhnard. "Studying Facebook via data extraction: the Netvizz application". In: ACM WEB SCIENCE CONFERENCE, 5., 2013, Paris. Anais... Paris: ACM, 2013. p. 1-10. Disponível em http:// thepoliticsofsystems.net/permafiles/rieder_websci.pdf. Acesso em 11/12/2017.

RIEDER, Berhnard. Netvizz v1.6, 2017. Disponível em https://apps.facebook.com/107036545989762/. Acesso em 23/1 1/2018.

SANTOS, Eliane Pereira; ALVES FILHO, Francisco. "O plurilinguismo no gênero comentário online: encontro e confronto entre muitas vozes sociais". Revista FSA, Teresina, v. 11, n. 2, p. 301-31 7, abr./ jun. 2014.

SILVA, Tomaz Tadeu da. "A produção social da identidade e da diferença". In: SILVA, Tomaz Tadeu da (Org.). Identidade e diferença: a perspectiva dos estudos culturais. 14. ed. Petrópolis: Vozes, 2014. p. 73-102.

VOLOCHÍNOV, Valentin. Marxismo e filosofia da linguagem: problemas fundamentais do método sociológico na ciência da linguagem. São Paulo: Editora 34, 2017.

VOLOCHÍNOV, Valentin Nikolaevich. "A construção da enunciação". In: VOLOCHÍNOV, Valentin Nikolaevich. A construção da enunciação e outros ensaios. São Carlos: Pedro e João Editores, 2013. p. 157-188. 
XAVIER, Antônio Carlos. Retórica digital: a língua e outras linguagens na comunicação mediada por computador. Recife: Pipa Comunicação, 2013.

Maria de Lourdes Rossi Remenche (mremenche@utfpr.edu.br) é doutora em Linguística pela Faculdade de Filosofia e Letras da Universidade de São Paulo (USP). Docente do Programa de Pós-Graduação em Estudos de Linguagens (PPGEL) da Universidade Tecnológica Federal do Paraná (UTFPR), Campus Curitiba, PR, Brasil.

Paulo Henrique Machado (phenrique14@yahoo.com.br) é mestre em Estudos de Linguagens pela Universidade Tecnológica Federal do Paraná (UTFPR), Campus Curitiba, PR, Brasil. Bacharel em Gestão da Informação pela Universidade Federal do Paraná (UFPR). Gestor da Informação na Prefeitura Municipal de Curitiba.

Nívea Rohling (nivear@utfpr.edu.br) é doutora em Linguística pela Universidade Federal de Santa Catarina (UFSC). Docente do Programa de Pós-Graduação em Estudos de Linguagens (PPGEL) da Universidade Tecnológica Federal do Paraná (UTFPR), Campus Curitiba, PR, Brasil.

\section{COMO CITAR ESSE ARTIGO DE ACORDO COM AS NORMAS DA REVISTA}

REMENCHE, Maria de Lourdes Rossi; MACHADO, Paulo Henrique; ROHLING, Nívea. "Discursividades sobre identidade, sexualidade e feminismo em redes sociais". Revista Estudos Feministas, Florianópolis, v. 28, n. 2, e60375, 2020.

\section{CONTRIBUIÇÃO DE AUTORIA}

Todo o trabalho (concepção, coleta/geração e análise de dados, elaboração do manuscrito, redação, discussão de resultados) foi produzido em total parceria.

\section{FINANCIAMENTO}

Não se aplica.

\section{CONSENTIMENTO DE USO DE IMAGEM}

Não se aplica.

APROVAÇÃO DE COMITÊ DE ÉTICA EM PESQUISA

Não se aplica.

\section{CONFLITO DE INTERESSES}

Não se aplica.

LICENÇA DE USO

Este artigo está licenciado sob a Licença Creative Commons CC-BY International. Com essa licença você pode compartilhar, adaptar, criar para qualquer fim, desde que atribua a autoria da obra.

\section{HISTÓRICO}

Recebido em 24/11/2018

Reapresentado em 15/09/2019

Aprovado em 11/11/2019 